\title{
A Comparative Study of English Vocabulary Learning Strategies Used by Iranian
}

\section{Bilinguals and Monolinguals}

\author{
Farzad Sabeki*, Rezvaneh Karimzadeh**
}

\begin{abstract}
The present study is an attempt to explore English vocabulary learning strategies employed by Iranian EFL undergraduate Baluch-Persian bilingual and Persian monolingual students in the University of Sistan and Baluchistan. The study utilized a between-groups research design. The participants of this study were 33 bilingual (Baluch-Persian) and 34 monolingual (Persian) students with an intermediate level of English. Their age ranged from 19 to 24. In order to collect the data, adapted version of Schmitt's (1997) Vocabulary Learning Strategy Questionnaire (VLSQ) with a five-point Likert scale was administrated. Data analysis included descriptive statistics and independent samples t-test. The results indicated that EFL students use a wide range of vocabulary learning strategies. Furthermore, the findings revealed that there was no statistically significant difference between bilinguals and monolinguals regarding English vocabulary learning strategies. Finally, the paper ends up with a number of pedagogical implications for English teachers.
\end{abstract}

Keywords: English vocabulary learning strategies, comparative, bilingual, monolingual, Baluch, descriptive statistics

This Article can be cited as:

Sabeki F., Karimzadeh R., (2020). A Comparative Study of English Vocabulary Learning Strategies Used by Iranian Bilinguals and Monolinguals, Journal of Arts and Social Sciences. VII (2), 1-10.

\footnotetext{
* Correspondence concerning this article should be addressed to Farzad Sabeki, MA in TEFL, University of Sistan \& Balucestan, Iran, sabekif@gmail.com .

** Rezvaneh Karimzadeh, MA in TEFL Department of Education, Saravan, Iran, r.krimzadeh1374@gmail.com.
} 


\section{Introduction}

Vocabulary can be defined in a number of ways based on the particular aspect from which it is approached. However, Folse (2004, p. 3) stated that "lack of vocabulary knowledge can stop the conversation". Similarly, Chastain (1988) suggests that the most common cause of learners' inability to make a successful communication during communication activities is the lack of needed vocabulary. Many linguists have stressed the vital role of vocabulary in the language (Chastain, 1988; Llach, 2011; Min, 2013; \& Zimmerman, 1997).

The important role of vocabulary in second language acquisition has been emphasized. According to Read (2000, p. 1), "words are the basic building blocks of language, the units of meaning from which the larger structures such as sentences, paragraphs, and whole texts are formed". In this regard, Nation (2001) claims that learning vocabulary items play a vital role in all language skills (listening, speaking, reading, and writing). However, today's language teachers and researchers have realized the important role of vocabulary in different pedagogical tasks. Undoubtedly, second language learners and their teachers are well aware of the fact that learning a second language involves the learning of large numbers of words (Mohseni-Far, 2007).

It is believed that lexical development is an integral component of second language learning and researchers have paid close attention to the need to develop this important sub-skill through the strategies to improve the language learners' vocabulary known as Vocabulary Learning Strategies (VLSs). Language learning strategies have been defined by O'malley and Chamot (1990, p. 7) as "the specific actions taken by the learner to make learning easier, faster, more enjoyable, more self-directed, and more effective". The shift from traditional teacher-centred approaches to modern learner-centred approaches made the learners more responsible and autonomous for their own learning.

In contrast with a couple of decades ago, finding people, who speak or understand more than one language, is as easy as $\mathrm{ABC}$. The human's lust for communication has been among the most important factors paving the way for bilingualism and multilingualism expansion throughout the world. Therefore, bilingualism and multilingualism sociocultural facts deserve to be extensively explored. Grant and Gottardo (2008) emphasize that the definition of bilingualism is complex and is influenced by multiple factors such as the age of acquisition of the second language, continued exposure to the first language, relative skill in each language and the circumstances under which each language is learned. Bilingualism of home and school is a worldwide phenomenon and as such has been dealt with rather positively in countries like Singapore, Canada, Switzerland and many more, through the introduction of systems of bilingual or multilingual education (Lambert, Genesee, Holobow, \& Chartrand, 1993). Iran, a multilingual and multicultural country with a population of more than 80 million people, is one of the most populous countries in the Middle East. Although Persian (Farsi) is the official language of the country, other languages like Turkish, Kurdish, Arabic, Baluchi and Armenian are spoken by minority groups in different parts of the country. As was formerly mentioned, Baluchi is also one of the languages spoken in Iran. Baluchi speakers mainly reside in Sistan and Bluchestan province in the southeast of Iran. There have always been differences in English language learning between bilingual Baluch-Persian speakers and Persian monolingual speakers. Such differences can be ascribed to a host of determining factors, among which bilingualism of Baluch students seems to be more influential. Bearing this point in mind, researchers in the present paper, aimed to investigate the similarities and differences of English vocabulary learning strategies among Baluch-Persian bilinguals and Persian monolinguals. Specifically, the present study sought to answer the following questions:

i. Is there any significant difference between Baluch-Persian bilinguals and Persian monolinguals in English vocabulary learning strategies?

ii. Is there any significant difference between Baluch-Persian bilinguals and Persian monolinguals regarding the most and the least vocabulary learning strategies? 


\section{Review of Literature}

\section{Vocabulary Learning Strategies}

According to Nation (2001), VLSs are a part of language learning strategies which in turn are a part of general learning strategies. However, better language learners generally use strategies appropriate to their own stage of learning and use a variety of strategies .Since the late 1970s, vocabulary learning strategies have gained much interest among many researchers and scholars who have attempted to define and classify vocabulary learning strategies. O'malley and Chamot (1990, p. 1) defined vocabulary learning strategies as "special thoughts or behaviors that individuals use to comprehend, learn or retain information" while R. Oxford (1990, p. 11) believes "...specific actions or behaviors accomplished by students to enhance learning". Another view regarding vocabulary learning strategies presented by P. Y. Gu (2005, p. 9) is "what learners utilize when confronted with a learning task" and these strategies are dependent on the learners themselves. As a result, vocabulary learning strategies can be defined as the learning style of individual learners that they utilize to enhance learning in an effective way.

As mentioned before VLSs have had received much attention. Yaacob, Shapii, Saad Alobaisy, AlRahmi, Al-Dheleai, Yahaya, \& Alamri (2019) examined vocabulary learning strategies employed by a group of Saudi Arabian learners in an EFL context. The results of this study revealed the percentage and frequency have further underscored this role and the significance of vocabulary learning in both students and teachers. Also, the results showed that students at SSM have employed the five categories of VLSs at a medium level and almost at a close range.

In another recent article Purnawarman (2019) investigated the frequency of vocabulary learning strategies used by Indonesian high school students and found out their knowledge of affixes as well as to figured out how their reported vocabulary learning strategies use relate to their knowledge of affixes. It was discovered that the participants used a medium level of frequency of vocabulary learning strategies with determination strategy most preferred by them. In addition, it was found that their affixes knowledge was low with multi, re-, inter-, dis-, -ful, and -er respectively considered as the order of their affixes acquisition. With respect to their interrelatedness, the overall participants' VLSs significantly contribute to their knowledge of affixes. However, unlike memory strategy, determination strategy proved to have no significant contributions to their affixes knowledge.

In another attempt, Nie \& Zhou (2017) explored a variety of vocabulary learning strategies adopted by some excellent English learners in the lengthy process of vocabulary learning and consolidating. They also discovered the relationship between the number of vocabulary learning strategies and the level of vocabulary. The results signaled that excellent language learner's vocabulary level tends to be in positive proportion to the number of his vocabulary learning strategies, with metacognitive strategies playing a most influential and decisive role.

Similarly, in another probe (Mokhtar, Rawian, Yahaya, Abdullah, \& Mohamed, 2017) identified the types of learners based on their VLSs preferences and discussed the impact of their preferences on the acquisition of English vocabulary. For this aim, a vocabulary learning questionnaire developed by (Y. Gu \& Johnson, 1996) was used to gather the data. Before the questionnaire was used, it was first translated to the Malay language and pilot-tested. Results showed that the respondents preferred guessing and dictionary strategies the most; the other five namely metacognitive regulation note taking strategies, rehearsal strategies, encoding strategies, and activation strategies were less preferred.

\section{Bilingualism and Strategy Use}

A large number of studies tended to mention the advantages in bilinguals over monolinguals in language acquisition especially when the learner's bilingualism is additive rather than subtractive (Cenoz, 2003). Similarly, bilingualism is regarded as one of the influential factors that seem to affect the use of language learning strategies. Many scholars in various countries conducted studies about monolingual and bilingual learners' learning strategies. The studies that have compared the strategies used by monolingual 
and bi/multilingual learners showed that multilingual learners are more flexible in using different strategies in comparison with monolingual learners (Cenoz, 2003).

In a very recent attempt, Thordardottir (2019) discovered the extent to which the language performance of school-age bilingual children is impacted by the amount of language exposure they have received in each language versus the timing of this exposure in terms of the age of first exposure (AoE). Receptive and expressive vocabulary and word morphology measures were administered in both languages to school-age simultaneous and sequential learners of French (other language English), and to their monolingual counterparts. Simultaneous bilinguals performed somewhat better than sequential bilinguals; however, both groups overall performed significantly more poorly than monolinguals. Differences in performance between simultaneous and sequential bilinguals were mediated by differences in the amount, not timing, of exposure. Sequential learners in grade 1 required lower amounts of input to reach high French scores than did their simultaneous counterparts; sequential and simultaneous learners in grade 3 did not differ in this respect. This finding suggests that the regency of bilingual exposure is a significant determiner of the rate of second language learning. The amount of exposure to each language since birth predicted performance in each language of the bilingual children.

An investigation conducted by Blom \& Boerma (2017) examined the effects of language impairment (LI) and bilingualism across vocabulary, morphology and verbal memory in a sample of children learning Dutch. In this experiment vocabulary was measured with the Peabody Picture Vocabulary Test, morphology with the Taaltoets AlleKinderen, verbal short-term (VSTM) and working memory (VWM) with forward and backward digit span tasks. Language knowledge (vocabulary, morphology) was affected by LI and bilingualism. Language processing (VSTM, VWM) was influenced by LI only. When language knowledge was controlled, the bilinguals outperformed the monolinguals on VSTM and VWM when TD and LI were collapsed. Bilingualism aggravated the effects of LI for vocabulary. Overall bilingualism may create a risk for the vocabulary knowledge of children with LI, but might be beneficial for their verbal memory.

Stolarova, Brielmann, Wolf, Rinker, Burke \& Baayen (2016) investigated the predictive value of childrelated and environmental characteristics for early lexical development. The German productive vocabulary of 512 -year-olds (27 girls), assessed via parental report, was analyzed taking children's gender, the type of early care they experienced, and their mono-versus bilingual language composition into consideration. The children were from an educationally homogeneous group of families and state-regulated daycare facilities with high structural quality. The small subgroup of bilingual children investigated exhibited slightly lower but still normative German expressive vocabulary size and a different vocabulary composition compared to the monolingual children. This study expanded current knowledge about relevant predictors of early vocabulary. It showed that in the absence of educational disadvantages the duration of early daycare experience of high structural quality is positively associated with vocabulary size but also points to the fact that environmental characteristics, such as type of care, might affect boys' and girls' early vocabulary in different ways.

Bialystok (2015) examined the effect of bilingualism on children's cognitive development and in particular, executive function. She describes studies reporting bilingual advantages in various tasks to identify the processor component of executive function that might be responsible for this bilingual advantage, discussing several possibilities, including inhibitory control. Finally, she proposed attention is a fundamental process that initiates developmental differences in bilingual children from as early as infancy.

\section{Methodology}

\section{Participants}

In order to compare vocabulary learning strategies used by Iranian bilinguals and monolinguals, 67 students were selected based on convenience sampling. Among these 33 students were bilinguals (speaking Baluchi and Persian as their L1) and 34 were monolinguals (only speaking Persian as their L1). Their age ranges between 19 and $25(M=22.28)$. All of the participants were Iranian EFL undergraduate students in the University of Sistan \& Baluchestan with an intermediate level of proficiency determined through and Oxford placement test. It is worthwhile to mention that Baluch bilingual students did not receive any Baluchi literacy (reading and writing) during their school. They all started Persian literacy until their graduation from school. In fact, Persian is the medium of instruction nationwide for all students. 


\section{Instrumentation}

This study mainly relied on Schmitt's VLSQ (1997) adapted by (Yu Wong, 2015). It is composed of 58 items, measured by five points Likert scale. It represented different vocabulary learning strategies proposed by Schmitt, including metacognitive (12 items), social (8 items), determination (6 items), memory (17 items) and cognitive ( 8 items), besides these, 8 items representing metacognitive regulation strategies were included. Metacognitive regulation strategies are the goal-setting and vocabulary-selection strategies, and self-initiation strategies to evaluate and monitor personal vocabulary learning progress (Y. Gu \& Johnson, 1996). Learners who used the most self-initiation strategies were observed to be more successful in vocabulary learning and were more proficient in language than other participants in Gu and Johnson's (1996) study. Despite the importance of metacognitive regulation strategies in vocabulary learning, these are not included in Schmitt's (1997) VLSQ or other taxonomies (R. Oxford, 1990). Furthermore, the questionnaire in this study included one item from Oxford's (1990) translation strategies category, "Write the meaning of new words in your native language", which is not included in Schmitt's VLSQ taxonomy. The translation is viewed as an efficient way to teach/learn grammar, syntax, and lexis of a foreign language (Mollaei, Taghinezhad, \& Sadighi, 2017). Reliability of this questionnaire was calculated using Cronbach's Alpha and turned out to be 0.92 which is an acceptable number.

Table 1. Cronbach's Alpha Reliability of Vocabulary Learning Strategies

\begin{tabular}{lll}
\hline Reliability Statistics & & \\
\hline Cronbach's Alpha & Cronbach's Alpha Based on Standardized Items & $\mathrm{N}$ of Items \\
0.921 & 0.920 & 58 \\
\hline
\end{tabular}

\section{Data Collection Procedure and Data Analysis}

For collecting the data, VLSQ was administered to participants. It took approximately 15 to 25 minutes to complete but the researchers informed students that there was no fixed time. The obtained data were coded in order of "always", "often", "sometimes", "seldom" and "never" as 5, 4,3, 2 and 1, respectively. After this phase, normality distribution of data, which is an assumption for parametric tests, was checked with the Kolmogorov-Smirnov test and a Sig. value of 0.17 was found which indicated data were normally distributed. Descriptive statistics and a number of independent samples t-test were run in order to compare overall vocabulary learning strategies used, and also for different strategies for two groups of bilinguals and monolinguals.

\section{Results of Vocabulary Learning Strategies}

In order to answer the first research question which is "Is there, any significant difference between Baluch-Persian bilinguals and Persian monolinguals in English vocabulary learning strategies?" descriptive statistics and an independent samples t-test was conducted.

Table 2. Statistics of Vocabulary Learning Strategy among Monolinguals and Bilinguals

\begin{tabular}{lllll}
\hline Groups & $\mathbf{N}$ & Mean & Std. Deviation & Std. Error of Mean \\
\hline Bilinguals & 33 & 3.1034 & .43237 & .07527 \\
Monolinguals & 34 & 3.1435 & .47462 & .08140 \\
Total & 67 & 3.1238 & .45131 & .05514 \\
\hline
\end{tabular}

According to (R. L. Oxford, 2003) learners with the mean score in the range above of 3.5 were considered as high strategy users, learners with the mean of 1 to 2.4 were low strategy users and the mean for medium strategy users was between 2.4 to 3.5. In the sample of this study regarding the means of vocabulary learning strategy use among bilinguals and monolinguals of intermediate level, both groups were considered as medium strategy users (table 2). 
An independent samples t-test was conducted to see the differences between bilinguals and monolinguals concerning vocabulary language learning strategies. There was no significant difference in using vocabulary language learning strategies among bilinguals $(\mathrm{M}=3.10, \mathrm{SD}=0.43)$ and monolinguals $(\mathrm{M}=3.14, \mathrm{SD}=0.47)$; [t $(65)=-0.361, \mathrm{p}=0.71$, two-tailed]. Therefore, the first null hypothesis which is "there is no significant difference between Baluch-Persian bilinguals and Persian monolinguals in English vocabulary learning strategies" is retained.

In order to answer the second research question "Is there any significant difference between bilinguals and monolinguals regarding the most and the least vocabulary learning strategies?" again descriptive statistics and a number of independent samples t-test were conducted to discover mean differences of bilinguals and monolinguals on each vocabulary learning strategy separately.

Table 3. Descriptive Statistics of Vocabulary Learning Strategies by Bilinguals and Monolinguals

\begin{tabular}{|c|c|c|c|c|c|c|c|c|}
\hline & & Translation & Metacognitive Regulatory & Metacognitive & Social & Determi & nMemory & y Cognitive \\
\hline \multirow{4}{*}{ Bilinguals } & $\mathbf{N}$ & 33 & 33 & 33 & 33 & 33 & 33 & 33 \\
\hline & $\mathbf{M}$ & 2.67 & 3.4667 & 3.0227 & 2.6591 & 3.1162 & 3.2525 & 3.1515 \\
\hline & SD & .957 & .72744 & .47974 & .65496 & 60307 & .55470 & .65607 \\
\hline & SEM & .167 & .12663 & .08351 & .11401 & .10498 & .09656 & .11421 \\
\hline \multirow[t]{4}{*}{$\overline{\text { Monolingua }}$} & & 34 & 34 & 34 & 34 & 34 & 34 & 34 \\
\hline & $\mathbf{M}$ & 3.38 & 3.5059 & 3.1422 & 2.6507 & 3.0392 & 3.2631 & 3.1912 \\
\hline & SD & 1.015 & .58721 & .52766 & .65191 & .68542 & .63081 & .69238 \\
\hline & SEM & .174 & .10071 & .09049 & .11180 & .11755 & .10818 & .11874 \\
\hline
\end{tabular}

Based on descriptive statistics provided in table 3, Baluch-Persian bilinguals preferred to use metacognitive regulatory, memory, cognitive, determination, metacognitive, translation and social strategies respectively. Baluch bilingual EFL students reported medium use of strategy categories since the mean of overall strategy use was 3.10 (table 2).

However Persian monolinguals, as it can be seen from table 3 used metacognitive regulatory, translation, memory, cognitive, metacognitive, determination and social strategies. Similarly, Persian monolingual EFL learners reported medium use of strategy categories with the mean of overall strategy 3.14 (table 2).

As table 3 displays, bilinguals' mean score for metacognitive regulatory, memory, cognitive, determination, metacognitive, translation, and social strategies are 3.46, 3.25, 3.15, 3.11, 3.02, 2.17 and 2.65 respectively. These numbers indicate that Baluch-Persian bilingual learners in the present study were more oriented toward using metacognitive regulatory and memory strategies than Persian monolingual learners. Conversely, monolinguals seem to be more inclined toward using metacognitive regulatory and translation strategies. Accordingly, for more precise and accurate results independent samples t-test was run for each category separately to check the significant difference between the most and the least vocabulary learning strategies used by bilinguals and monolinguals.

Table 4. Results of independent samples t-test among bilingual and monolingual EFL learners English VLS use

\begin{tabular}{llllll}
\hline & F & Sig. & t & df & Sig. (2-tailed \\
\hline Translation & 0.514 & 0.476 & -2.96 & 65 & 0.004 \\
Metacognitive Regulatory & 1.913 & 0.171 & -0.243 & 65 & 0.80 \\
Metacognitive & 0.015 & 0.903 & -0.968 & 65 & 0.336 \\
Social & 0.278 & 0.600 & 0.052 & 65 & 0.958 \\
Determination & 0.007 & 0.934 & 0.487 & 65 & 0.628 \\
Memory & 0.209 & 0.649 & -0.073 & 65 & 0.942 \\
Cognitive & 0.105 & 0.747 & -0.241 & 65 & 0.811 \\
\hline
\end{tabular}


Independent samples t-test was run to see any significant difference between bilinguals and monolinguals in terms of using translation strategies. The result of Levene's Test $[\mathrm{F}=0.51 ; \mathrm{p}=0.476]$ indicated equality of variances. Furthermore, the results of the t-test $[t(65)=-2.96 ; p<0.05]$ indicated there was a significant difference in using translation strategies by bilinguals and monolinguals and the means revealed that monolinguals used translation strategies much more than their bilingual counterparts.

About meta cognitive regulatory strategies, the results of Levene's Test not only for this category but also for all categories showed equality of variances (table 4). The results of the $t$-test $[t(65)=0.17 ; p=0.80]$ showed that there was not any significant difference in using metacognitive regulatory strategies between bilinguals and monolinguals and the means indicated monolinguals used metacognitive regulatory strategies more.

Concerning next strategy which is metacognitive, the results of the t-test [t $(65)=-0.96 ; p=0.33$ ] revealed that, there was not any significant difference in using metacognitive strategies between bilinguals and monolinguals and the means indicated monolinguals used metacognitive strategies more.

As regards social strategies, the results of the $t$-test $[t(65)=0.52 ; p=0.95]$ showed there was not any significant difference in using social strategies between bilinguals and monolinguals and comparison of the means indicated monolinguals and bilinguals used social strategies to an equal extent.

For determination strategies, the results of the $t$-test [ $t(65)=0.48 ; \mathrm{p}=0.62]$ signaled that there was not any significant difference in using metacognitive strategies between bilinguals and monolinguals and the means indicated bilinguals used determination strategies more.

Regarding memory strategies, the results of the t-test [t $(65)=-0.07 ; \mathrm{p}=0.94]$ indicated that there was not any significant difference in using memory strategies between bilinguals and monolinguals and the means showed monolinguals used memory strategies more.

And finally concerning cognitive strategies the results of the $t$-test $[t(65)=-0.24 ; p=0.81]$ revealed that there was not any significant difference in using cognitive strategies between bilinguals and monolinguals and the means indicated monolinguals used cognitive strategies more.

\section{Discussion}

The aim of the current paper was twofold: 1) to explore English vocabulary learning strategies employed by Iranian EFL undergraduate bilingual and monolingual students, 2) to find out the most and least VLSs used by bilingual and monolingual. Regarding the first aim of the research, the findings showed that there was no significant difference in using overall vocabulary learning strategies among BaluchPersian bilinguals and Persian monolinguals. Concerning the second aim, it can be concluded that BaluchPersian bilingual learners in the present study used metacognitive regulatory and memory strategies more than Persian monolingual learners. On the other hand, monolinguals used metacognitive regulatory and translation strategies.

The findings of this study are in harmony with the results of Sazvar \& Varmaziyar (2017) who concluded that there was no significant difference between monolinguals and bilinguals in terms of using vocabulary learning strategies. Both bilingual Arab-Persian and monolingual Persian students showed medium use of vocabulary learning strategies. Another research also confirmed that no significant difference was seen between Arab-Persian Bilinguals and Persian Monolinguals in L3 recognition vocabulary learning. Studies also reported that there was no significant difference between the performance of bilinguals and monolinguals regarding their performances on reading comprehension (Mokhtari Khiyavi, Rostami, \& Gholami, 2016; Saffarian, Gorjian, \& Nejad Fazel, 2013).

So far, numerous studies reported that bilinguals outperformed their monolingual counterparts in different tasks including linguistic knowledge, cognitive flexibility, better problem solving and higherorder thinking skills (Zarghami \& Bagheri, 2014), but despite that, the impact of bilingualism on vocabulary learning in general and on vocabulary learning strategies in particular still remains as a controversial issue (Yu Wong, 2015; Zare \& Davoudi, 2013). 


\section{Conclusion and Implications}

The main objective of the current paper was to ascertain whether there was any significant difference among English VLSs employed by Baluch-Persian bilinguals and Persian monolinguals. The results showed that there was no significant difference in overall English VLSs between the two groups.

Besides the theoretical implications, a number of pedagogical implications are addressed in this section. Teachers should assist students in becoming independent learners during the course of L2 vocabulary learning. Lotfi (2007) states that this could be achieved through instructing learners to apply vocabulary learning strategies as efficiently as possible. Moreover, Goundar (2015, p. 298) believes that "The concept of good learners is very clear that those learners who are able to employ various strategies are more successful in acquiring vocabulary than those who choose to use fewer strategies". Therefore, teachers need to expose learners to various strategies and methods of vocabulary learning.

Finally, language teachers need to make learners conscious of their need to develop an independent and structured approach to language learning, which has been shown to be mostly associated with vocabulary learning success.

\section{References}

Bialystok, E. (2015). Bilingualism and the Development of Executive Function: The Role of Attention. Child Development Perspectives, 9(2), 117-121. Retrieved from https://onlinelibrary.wiley.com/doi/abs/10.1111/cdep.12116. doi:10.1111/cdep.12116

Blom, E., \& Boerma, T. (2017). Effects of language impairment and bilingualism across domains. Linguistic Approaches to Bilingualism, 7(3), 277-300.

Cenoz, J. (2003). The additive effect of bilingualism on third language acquisition: A review. International Journal of Bilingualism, 7(1), 71-87. $\quad$ Retrieved from https://journals.sagepub.com/doi/abs/10.1177/13670069030070010501. doi:10.1177/13670069030070010501

Chastain, K. (1988). Developing second-language skills: theory and practice. San Diego: Harcourt Brace Jovanovich.

Folse, K. S. (2004). Myths about teaching and learning second language vocabulary: What recent research says. TESL Reporter, 37(2), 1-13.

Goundar, P. (2015). Vocabulary Learning Strategies of English as a Foreign Language (EFL) Learners: a Literature Review.

Grant, A., \& Gottardo, A. (2008). Defining Bilingualism. In Encyclopedia of Language and Literacy Development (pp. 1-7).

Gu, P. Y. (2005). Vocabulary learning strategies in the Chinese EFL context. Singapore: Marshall Cavendish Academic.

Gu, Y., \& Johnson, R. K. (1996). Vocabulary Learning Strategies and Language Learning Outcomes. Language Learning, 46(4), 643-679. Retrieved from https://onlinelibrary.wiley.com/doi/abs/10.1111/j.1467-1770.1996.tb01355.x. doi:10.1111/j.14671770.1996.tb01355.x

Lambert, W. E., Genesee, F., Holobow, N., \& Chartrand, L. (1993). Bilingual education for the majority of English-speaking children. European Journal of Psychology of Education, 8(1), 3-22. doi:10.1007/BF03172860 
Llach, M. P. A. (2011). Lexical Errors and Accuracy in Foreign Language Writing: Channel View Publications.

Lotfi, G. (2007). Learning Vocabulary in EFL Contexts through Vocabulary Learning Strategies.

Min, Y. K. (2013). Vocabulary acquisition: practical strategies for ESL students. Journal of International Students, 3(1), 64-69.

Mohseni-Far, M. (2007). Techniques and Strategies Utilized for Vocabulary Acquisition: the necessity to design a multifaceted framework with an instructional wise equilibrium. Porta Linguarum, 8, 137152.

Mokhtar, A. A., Rawian, R. M., Yahaya, M. F., Abdullah, A., \& Mohamed, A. R. (2017). Vocabulary learning strategies of adult ESL learners. The English Teacher, 12.

Mokhtari Khiyavi, B., Rostami, G., \& Gholami, H. (2016). Effects of Bilingualism and Monolingualism on Iranian EFL Learner s' performance on Reading Comprehension Test. Journal of Applied Linguistics and Language Research, 3(4), 225-233.

Mollaei, F., Taghinezhad, A., \& Sadighi, F. (2017). Teachers and Learners' Perceptions of Applying Translation as a Method, Strategy, or Technique in an Iranian EFL Setting. 2017, 5(2), 7. Retrieved from http://www.journals.aiac.org.au/index.php/IJELS/article/view/3407. doi:10.7575/aiac.ijels.v.5n.2p.67

Nation, I. S. P. (2001). Learning vocabulary in another language. Retrieved from http://dx.doi.org/10.1017/CBO9781139524759.

Nie, Y., \& Zhou, L. (2017). A study of vocabulary learning strategies used by excellent English learners. Research on Modern Higher Education, 4, 101-106.

O'malley, J. M., \& Chamot, A. U. (1990). Learning strategies in second language acquisition: Cambridge university press.

Oxford, R. (1990). Language learning strategies. New York, 3.

Oxford, R. L. (2003). Language learning styles and strategies: Mouton de Gruyter.

Purnawarman, P. (2019). EFL students' vocabulary learning strategies and their affixes knowledge. Journal of Language and Linguistic Studies, 15(1), 262-275.

Read, J. (2000). Assessing vocabulary: Cambridge university press Cambridge.

Saffarian, R., Gorjian, B., \& Nejad Fazel, A. (2013). Effects of Bilingualism and Monolingualism on EFL Learners' Performance on Reading Comprehension Test. Advances in Asian Social Science (AASS) $820,4(2), 820-823$.

Sazvar, A., \& Varmaziyar, H. (2017). English Vocabulary Learning Strategies: the Case of Iranian Monolinguals vs. Bilinguals. Journal of English Language Teaching and Learning, 19, 169-196.

Tolarova, M., Brielmann, A. A., Wolf, C., Rinker, T., Burke, T., \& Baayen, H. (2016). Early vocabulary In relation to gender, bilingualism, type, and duration of childcare. Advances in cognitive psychology, 12(3), 130. 
Thordardottir, E. (2019). Amount trumps timing in bilingual vocabulary acquisition: effects of input in simultaneous and sequential school-age bilinguals. International Journal of Bilingualism, 23(1), 236-255.

Yaacob, A., Shapii, A., Saad Alobaisy, A., Al-Rahmi, W. M., Al-Dheleai, Y. M., Yahaya, N., \& Alamri, M. M. (2019). Vocabulary Learning Strategies Through Secondary Students at Saudi School in Malaysia. SAGE Open, 9(1), 2158244019835935. Retrieved fromhttps://journals.sagepub.com/doi/abs/10.1177/2158244019835935. doi:10.1177/2158244019835935

Yu Wong, E. M. (2015). A Case Study of the Vocabulary Learning Strategy Use of Twenty Chinese ESL Learners in Australia. (Doctor of Education (EdD)), Griffith University.

Zare, M., \& Davoudi, S. (2013). Effects of bilingualism on L3 vocabulary learning among Iranian EFL learners (Vol. 13).

Zarghami, S., \& Bagheri, M. S. (2014). The Impact of Bilingualism on English Vocabulary Learning Among Middle School Students. Journal of Studies in Learning and Teaching English, 2(5), 4160.

Zimmerman, C. B. (1997). Historical trends in second language vocabulary instruction. Second language vocabulary acquisition, 5-1. 